\section{ECCOMAS}

\section{Proceedia}

COMPDYN 2021

$8^{\text {th }}$ ECCOMAS Thematic Conference on Computational Methods in Structural Dynamics and Earthquake Engineering

M. Papadrakakis, M. Fragiadakis (eds.) Streamed from Athens, Greece, 28 - 30 June 2021

\title{
CALIBRATION AND NUMERICAL MODELING OF RC BEAM- COLUMN JOINTS DESIGNED FOR GRAVITY LOADS
}

\author{
Marcello Sabene ${ }^{1}$, Maria Zucconi ${ }^{1}$, Stefano Pampanin ${ }^{2}$, and Barbara Ferracuti ${ }^{1}$ \\ ${ }^{1}$ Niccolò Cusano University \\ Via Don Carlo Gnocchi 3, 00166, Rome, Italy \\ e-mail: \{marcello.sabene, maria.zucconi, barbara.ferracuti\}@unicusano.it \\ ${ }^{2}$ Department of Structural and Geotechnical Engineering, Sapienza University of Rome \\ Via Eudossiana 18, 00184, Rome, Italy \\ stefano.pampanin@uniroma1.it
}

\begin{abstract}
Damage reports after recent earthquakes prove that the structural deficiencies of non-ductile Reinforced Concrete (RC) buildings often lead to structural element local damage and collapse of the entire structure. The structural weakness of the Beam-Column joints, due to the absence of seismic detailing and capacity design principles, plays a key role in the seismic vulnerability of European building stock designed before the 1970's, thus before the introduction of modern seismic codes. In RC buildings subjected to reversed cyclic earthquake loads, high stress concentration occurs at the Beam-Column joints, making these regions prone to the occurrence of severe damage and brittle mechanisms. Yet, a common engineering practice consists in modeling the Beam-Column joints as rigid elements in concrete frames, neglecting the joint's deformability and, more importantly, their actual local mechanism. Consequently, the predicted stiffness and the collapse mechanisms of the structure can, unconservatively, change significantly from the actual one. Starting from the experimental results available in literature, this work aims at calibrating the key parameters that characterize the equivalent joint momentrotation hysteresis behavior of existing substandard Beam-Column joints, by using a simple while reliable lumped plasticity modeling approach. The numerical model was developed in OpenSees and validated on many experimental results collected from the literature. The global joints response relationships under cyclic loads, defined as a function of the joint structural detailing and the axial load, satisfactorily reproduce the experimental findings in terms of first cracking point, yielding point, overall hysteretic behavior, pinching effect, and strength degradation. Moreover, the initial and post-yielding stiffness values of the joint's backbone curve were further improved when compared to those recently proposed by the NZSEE2017 Seismic Assessment Guidelines.
\end{abstract}

Keywords: Earthquake Engineering, Existing Buildings, Beam-Column Joints, Numerical Calibration, Cyclic Analysis. 


\section{INTRODUCTION}

Several studies on the seismic behavior of reinforced concrete joints within existing frames in seismic areas have been carried out in the last few decades. The brittle failure of joint panels has been recorded more frequently, following the most recent seismic events [1], which, in addition to extensive structural damages, have caused great economic losses [2-5] and highlighted the strong vulnerability of pre-70's buildings [6-9].

In $\mathrm{RC}$ frame structures stressed only by gravity loads, joint panel regions are rarely subjected to significant stresses, but the situation is rather different when considering seismic actions. Therefore, a very high stress state is generated in the joint region, where specific transverse/shear reinforcement should be adopted to reduce the stress variation. Instead, older frame buildings are typically characterized by poor reinforcement detailing, poor bond properties, inadequate confinement, and more importantly, lack of capacity design principles.

As shown in many experimental programs, the joint panels of pre-70's were characterized by insufficient tensile strength due to the absence or lack of horizontal and vertical reinforcement. This weakness appears clearly with the joint failure induced usually by shear or bond flaws [9-11]. The flexural and shear forces, generated into the joint panel by the cyclic tests, create a stress distribution transferred through the joint, producing a wide diagonal crack pattern along the principal compressive directions. This pattern leads to either a tensile failure or to a compression/crushing failure of the diagonal strut, and thus to a strength and stiffness deterioration within the joint. In other cases, the joint failure occurred with the instability of the vertical column bars, devoid of horizontal reinforcements, i.e., stirrups or wall beam bars.

Therefore, growing attention in the literature has been focused on the analytical/numerical modeling of gravity load designed RC beam-column, considering the joint panel zone's deformability and capacity [12-14]. In the last decades, many numerical models have been developed and proposed either based on Finite Elements (FE) modeling, or on simplified macromodels or lumped plasticity (e.g. [15-19]) and analytical approaches (e.g. [20]).

The present work analyzes experimental tests conducted on the external joints with the aim to verify the accuracy of the proposed constitutive laws. In particular, the response prediction obtained by a simple moment-rotation backbone, whose parameters are defined a priori based on current knowledge on the topic, with respect to a more complex backbone calibrate ad-hoc from the experimental results. Taking one of these nodes as a case study, a numerical model was built in OpenSees based on a lumped plasticity approach and relying upon a joint rotational spring. Two different relations have been defined: a bi-linear relationship based on the NZSEE2017 Seismic Assessment Guidelines and associated literature [15, 21] and a more refined tri-linear relationship that better approximates the first cracking point, the elastic and softening branches. The hysteresis behavior was modeled trough the use of a "uniaxial hysteretic material" already presents in OpenSees library. Regarding the other tests analyzed, only the parameters useful for defining their backbone curve are reported.

\section{EXPERIMENTAL STUDIES ON RC JOINT SUBSYSTEMS}

In literature, several experimental studies on beam-column joints with non-ductile detailing have been carried out to understand the as-built parameters that would influence the seismic performance of these structural connections.

In the last decades many exterior beam-column joints, representatives of pre-1970s construction and/or gravity-only design buildings, characterized by inadequate joint shear reinforcements, inadequate bond resistance, and non-ductile beam anchorage details by modern standards, were tested with the aim to assess the seismic behavior of these connections (e.g. [9-11]), several 
design methodologies were developed (e.g. [15-19]) and nowadays suitable types of reinforcement interventions were investigated (e.g. [22-27]). In general terms, depending on the structural detailing adopted and on the axial load variation assumed, the failure modes of beamcolumn connections can be significantly different, so they need to be checked on a case-by-case basis. To this aim, the moment - axial load performance domain and the hierarchy of strength approach can be used to evaluate the sequence of the collapse events between beam, column, and joint panel zone [28].

Considering the typical structural weaknesses of existing RC buildings, in the late 1990s and early 2000s, Pampanin et al. carried out quasi-static tests on existing RC beam-column joint subsystems considering plain-round reinforcements with end-hook anchorages, under quasistatic cyclic loading and varying column axial load according to the European construction practice of the 1950-1970s period [7-9]. Further comprehensive experimental and numerical testing campaigns on beam-column joint subassemblies have been carried out at the University of Canterbury (2002-2010) [29-31]. Test results [30] and numerical simulations [32] revealed extensive shear damage in the joint panel zone, which would lead to a severe and critical reduction of lateral and gravity load capacity of the overall frame system. The implication of joint damage and collapse within the frame system collapse mechanism become up a crucial issue in recent days.

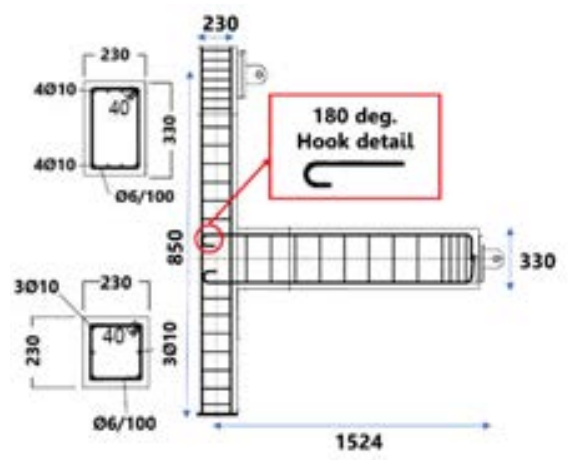

(a)

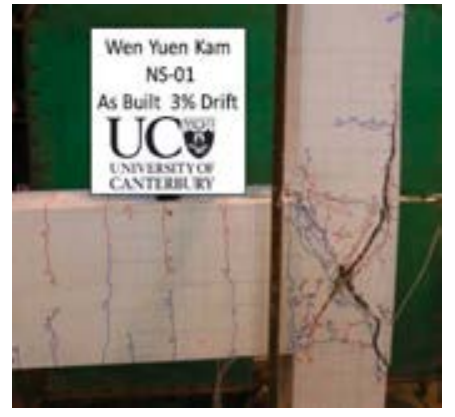

(b)

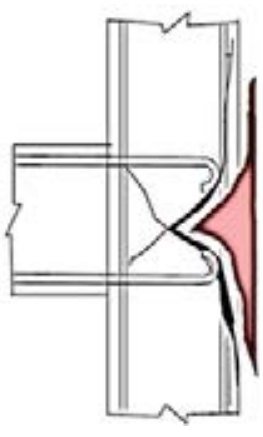

(c)

Figure 1: (a) Reinforcing and geometry details for test unit NS-O1 [30], (b) cracks pattern at top drift equal to 3\% [30], (c) "concrete wedge" mechanism formation [15].

In this paper, the $2 / 3$-scaled exterior beam-column joint unit NS-01, belonging to the experimental tests carried out by University of Canterbury UC research team [31], shown in Figure 1 , was selected to begin the direct calibration of the moment-rotation relationship key parameters, starting from the values suggested by NZSEE Seismic Assessment Guidelines and associated literature $[15,21]$. The chosen specimen is characterized by plain-round reinforcements with end-hook anchorages and tested under a unidirectional quasi-static cyclic lateral loading. The geometry of the trial specimen was chosen to be close to the pre-1970s non-ductile RC beam-column joint benchmark, see Figure 1 (a). Deformed mild steel reinforcements and commercial pre-mix concrete compression strength of $30 \mathrm{MPa}$ were used. The lateral loading protocol used in this test consisted of two displacement-controlled cycles at increasing amplitudes: $0.1 \%, 0.2 \%, 0.5 \%, 1.0 \%, 1.5 \%, 2.0 \%, 2.5 \%, 3.0 \%$ and $4.0 \%$ inter-story drift. The lateral load was coupled with a varying axial loading, $\mathrm{N}$, as suggested since [9], to simulate the actual frame sway action, as per the experimental test, considering $\mathrm{N}$ as a function of the lateral load $F_{C}$ : $N=110 \mathrm{kN} \pm 4.63 F_{C}$. Most previous literature experiments on beam-column joint subassemblies (for both existing capacity and retrofit solution evaluations) have used either constant or 
zero column axial loads, so the chosen test represent an interesting case- study. The specimen NS-01 showed a crack pattern that develops along the main principal compressive direction at a top drift value equal to 3\% (end of the test), as represented in Figure 1 (b). In addition, the punching action from the smooth bars with end up develops the so called "concrete wedge" mechanism $[9,7,15]$, due to the development of stresses in the only portion of the joint panel unconfined (no stirrups, no convergent beam), see Figure 1 (c).

In the next sections, the numerical lumped plastic model approach used to evaluate the global force-top drift curve of the proposed experimental test is described along with the various parameters used for evaluating pinching behavior, unloading, and reloading stiffness degradation, strength degradation, and energy dissipation.

\section{NUMERICAL MODELING APPROACH}

The numerical model adopted to reproduce the experimental test was implemented in OpenSees. For the overall system, a finite element lumped plasticity approach was used, considering for the converging elements a linear-elastic region in the middle and the inelasticity concentrated at the ends. The plastic hinge length was evaluated by using the Priestley formulation [12].

Regarding the joint panel strength-deformation capacity and its non-linear behavior, a simplified macro-model approach was adopted $[7,9,15]$. Thus, joints behavior both in linear and nonlinear range was considered through a single rotational spring placed in its core region.

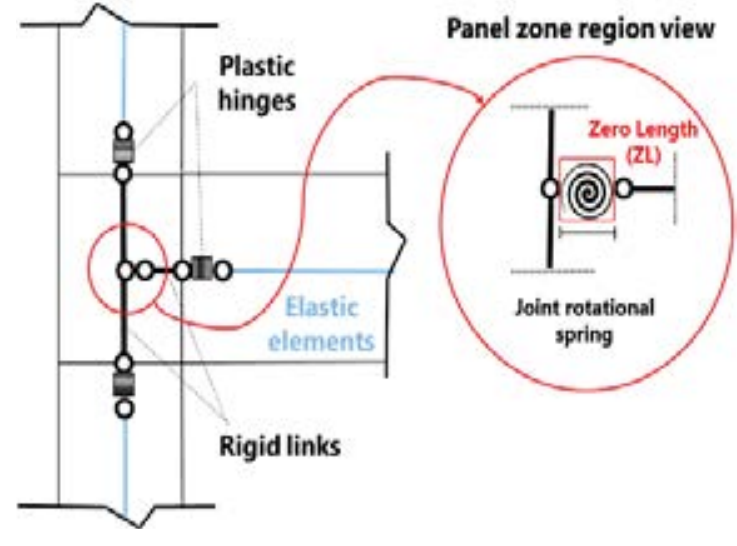

(a)

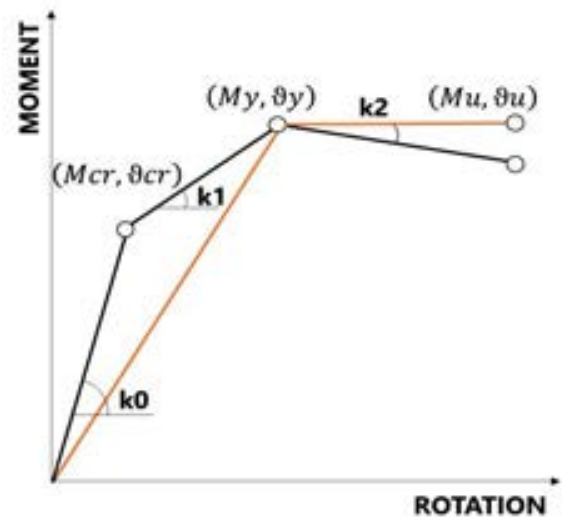

(b)

Figure 2: (a) Numerical model performed in OpenSees, (b) bi-linear and tri-linear Backbones.

The rotational spring was linked to beam and column interfaces with rigid links. All plastic hinges non- linearities were included through Zero Length (ZL) elements at the end of the members and in the joint panel, see Figure 2 (a). Once the numerical model has been defined, two backbone types have been used to reproduce the experimental test. The simplest envelope curve, orange line of Figure 2 (b), represents a bi-linear constitutive relationship defined according to the parameters from the NZSEE2017 Seismic Assessment Guidelines [21]; while a more refined version, black line of Figure 2 (b), considers, through a trilinear constitutive relationship, the pre-cracking stage and the softening behavior after the peak. In both curves, the pairs of points $(M, \vartheta)$ with the subscript " $y$ " and " $u$ " define the yielding condition and the ultimate condition, respectively. Notably, while the yielding point is the same for both curves, the ultimate points are different. Only for the tri-linear backbone curve, the first cracking condition has been defined and indicated with the subscript " $c r$ " in the black curves of Figure 2 (b), thus forming a knee that anticipates the yielding point. The next section will discuss the parameters 
governing the capacity and the hysteretic uniaxial material used for both the bi/tri-linear backbone.

\subsection{JOINT MOMENT-ROTATION HYSTERESIS BACKBONE}

The joint spring capacity in terms of bending moment can be derived from the principal tensile or compressive stresses, where they consider the axial load acting on the top of the column.

For a joint with no horizontal confinement provided by the stirrups $\left(\sigma_{h}=0\right)$, its capacity, expresses in terms of moment resistance $M_{\text {joint }}$, both in pull and push directions, has been determined by using the following equations:

$$
\begin{aligned}
& M_{\text {joint }}=\frac{v_{j h} / A_{c}}{\phi}=\frac{V_{j h}}{\phi} \\
& v_{j h}=\sqrt{p_{t, c}^{2} \pm p_{t, c}\left(\frac{N_{V}}{A_{c}}\right)} \\
& \phi=\frac{2 L^{\prime}{ }_{b} L_{c}-1.8 d L_{b}}{L_{b} 0.9 d A_{C}\left(L_{c}-L_{b}\right)}
\end{aligned}
$$

In (1) $v_{j h}$ is the horizontal shear stress, $A_{c}$ represents the column cross section area, and $V_{j h}$ is the horizontal shear force acting at the mid-depth of the joint core. In (2) $p_{t, c}$ are the principal tensile or compressive stresses, evaluated by using the Mohr circle while $N_{V}$ represents the axial load acting on the top of the column. In (3) $\phi$ is a geometric term which depends on the joint subsystem dimensions and on the lever arm $d$. All the terms reported in Equations (1), (2), (3) are represented in Figure 3, while push direction implicates beams upper fibers in compression state and pull direction the tension one. For the complete procedure, refer to NZSEE2017 Seismic Assessment Guidelines and associated literature [15, 21, 23]. For the analyzed test, the bending moment capacity results equal to $35.5 \mathrm{kNm}$ in push-direction and $27.5 \mathrm{kNm}$ in pull direction. Concerning the rotation corresponding to the maximum bending moment, actually no formulations are available and the proposed value by the NZSEE2017 Seismic Assessment Guidelines [21] are independent from the construction details and geometry parameters.

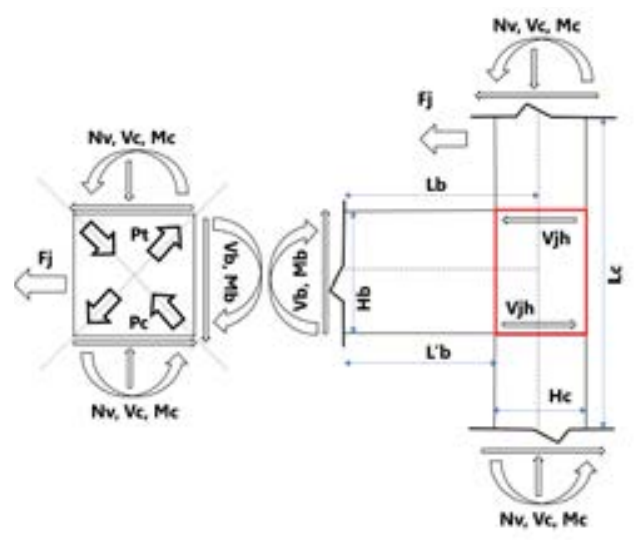

Figure 3: Moment, shear, and stresses at joint region and, Free-body diagram of a beam-column joint subassembly (push direction). 
Moreover, no indication on the pre-cracking stage is available, because on the safe side the NZSEE2017 neglects the pre-cracking stage.

Therefore, in the present work a preliminary calibration of the parameters governing the precracking stage is performed based on the analyzed experimental test.

To model the cyclic behavior of the joint panel (e.g. $[15,33])$, a hysteretic uniaxial material was adopted in OpenSees library. In addition to the envelope parameters, the initial elastic stiffness $K_{0}$ and the pairs of points of the envelope $(M, \vartheta)$, the cyclic model, represented in Figure 4 , requires the definition of several inputs parameters such as Pinch- $x / y$ pinching factor for rotation/moment during the reloading branches, Damage 1 due to ductility $(\mu)$, Damage 2 due to energy dissipation, and finally the power unloading stiffness $(\beta)$, which governs the cycles stiffness degradation; they are all schematized in Tab. 1. The calibrated parameters used in the numerical model are: Pinch $_{x}=0.3$, Pinch $_{y}=0.05$, Damage $_{1}=0.02$, Damage $_{2}=0, \beta=$ 0.5 .

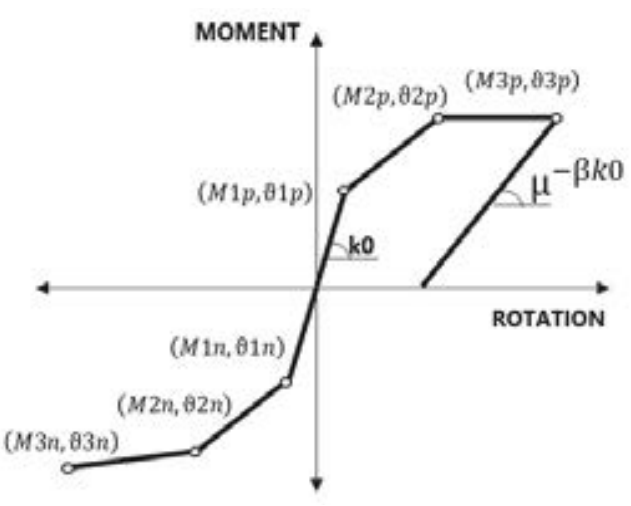

\begin{tabular}{|c|c|}
\hline \multicolumn{2}{|r|}{ Hysteretic Material Parameters } \\
\hline & Elastic stiffness \\
\hline$(M, \vartheta)$ & $\begin{array}{l}\text { Moment and Rotation points of the en- } \\
\text { velope }\end{array}$ \\
\hline Pinch $_{x}$ & $\begin{array}{l}\text { Pinching factor for rotation during re- } \\
\text { loading }\end{array}$ \\
\hline Pinch $_{y}$ & $\begin{array}{l}\text { Pinching factor for moment during re- } \\
\text { loading }\end{array}$ \\
\hline Damage $_{1}$ & Damage due to ductility $(\mu)$ \\
\hline Damage $_{2}$ & Damage due to energy dissipation \\
\hline$\beta$ & $\begin{array}{l}\text { Power used to determine the degraded } \\
\text { unloading stiffness }\end{array}$ \\
\hline
\end{tabular}

Figure 4: (a) Hysteretic material backbone, (b) Hysteretic material input parameters

The adopted hysteretic model shows the advantage to manage independently the positives (first quadrant) and negatives (third quadrant) notable points of the envelope, with subscripts "p" and " $n$ " in Figure 4. This opportunity allows to account the non-symmetric response of the subsystem in the two directions, push and pull directions, of the seismic action as shown by many experimental tests

\section{EXTERIOR JOINT MODEL CALIBRATION AND RESULTS}

The bi-linear backbone (BB) and tri-linear backbone (TB) are both adopted to reproduce the experimental response of NS-O1 joint panel. The first simplest backbone is an elastic perfect plastic one and its parameters are defined thanks to the actual guidelines (blind prediction), instead the parameters of the second one is calibrated ad-hoc to match the experimental response on the basis of the analyzed experimental test. As will be shown, both the models capture the experimental test with a slight, and expected difference in the level of accuracy.

In Table 1, all the parameters that characterize the envelope curves are reported, both for bilinear backbone (BB) and tri-linear backbone (TB). For both the backbones, the parameters governing loading and reloading branches are set equal to Pinch- $\mathrm{x}=0.3$, Pinch- $\mathrm{y}=0.05 \mathrm{D}_{1}=0.02$, $\beta=0.5$, and the maximum bending moment $M_{y}$ was calculated according to eq. (1) for push 
direction, while it was reduced of about $22 \%$ in pull direction. Concerning the rotations at yielding and ultimate condition, for the elastic perfectly plastic backbone they are set equal to those proposed by NZSEE2017 Seismic Assessment Guidelines [21] in both directions, while for the trilinear backbone based on the experimental test, they result slightly higher in both the directions.

\section{Proposed envelope curves for specimen NS-01}

\begin{tabular}{cccccccccc}
\hline Model & $\begin{array}{c}\mathrm{M}_{c r} \\
(\mathrm{kNm})\end{array}$ & $\begin{array}{c}\mathrm{M}_{y} \\
(\mathrm{kNm})\end{array}$ & $\begin{array}{c}\mathrm{M}_{u} \\
(\mathrm{kNm})\end{array}$ & $\begin{array}{c}\mathrm{K}_{0} \\
(\mathrm{kN} / \mathrm{m})\end{array}$ & $\begin{array}{c}\mathrm{K}_{1} \\
(\mathrm{kN} / \mathrm{m})\end{array}$ & $\begin{array}{c}\mathrm{K}_{2} \\
(\mathrm{kN} / \mathrm{m})\end{array}$ & $\begin{array}{c}\vartheta_{\mathrm{cr}} \\
(\mathrm{rad})\end{array}$ & $\begin{array}{c}\vartheta_{\mathrm{y}} \\
(\mathrm{rad})\end{array}$ & $\begin{array}{c}\vartheta_{\mathrm{u}} \\
(\mathrm{rad})\end{array}$ \\
$\mathrm{BB}$ & - & +27.5 & +27.5 & +1364 & - & 0 & - & \pm 0.005 & \pm 0.01 \\
& & -35.5 & -35.5 & -1618 & & & & & \\
TB & +16 & +27.5 & +22 & +3142 & +474 & -19 & +0.00085 & \pm 0.0075 & +0.015 \\
& -20.5 & -35.5 & -28.4 & +2150 & +658 & -106 & -0.001 & & -0.012 \\
\hline
\end{tabular}

Table 1: Backbone values used in NS-O1 numerical model.

The axial load protocol used in the numerical analysis was back calculated from the experimental data, where the axial load was imposed during the test. The cyclic analyses in terms of lateral force vs top drift results for NS-O1 are compared with the test results, as shown in Figure 5 (a), (b).

Figure 5 (a) shows the comparison between the experimental test and numerical model with elasto-plastic backbone, while Figure 5 (b) shows the same comparison using a tri-linear backbone curve. Looking at the numerical bi-linear backbone of Figure 5 (a), the stiffness $K_{0}$ is equal to $1364 \mathrm{kN} / \mathrm{m}$ for the pull and $1618 \mathrm{kN} / \mathrm{m}$ for push loading, respectively. This value was $50 \%$ and $16 \%$ lower than the experimental one equal to $2730 \mathrm{kN} / \mathrm{m}$ in the pull direction and $1926 \mathrm{kN} / \mathrm{m}$ in the push direction, respectively. The stiffness $K_{0}$ under-estimation observed in the cyclic analyses is due to the fact that the elastic perfectly plastic backbone neglecting the pre-cracking stage.

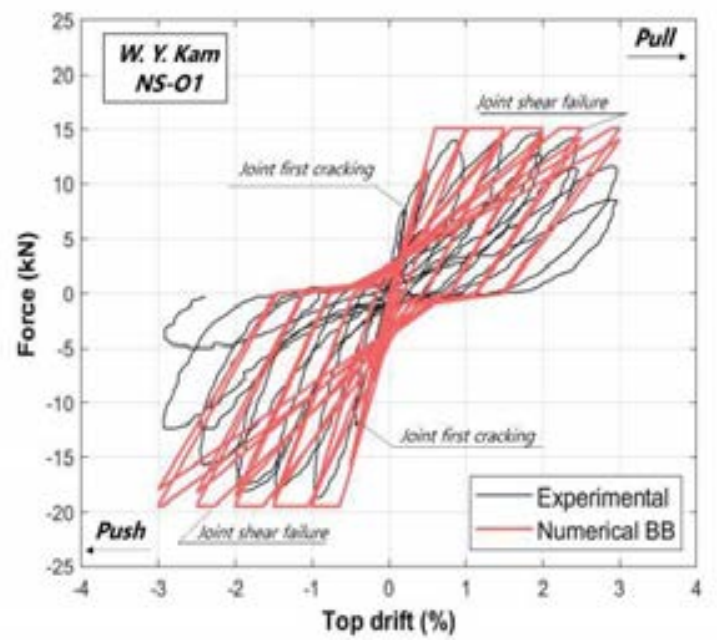

(a)

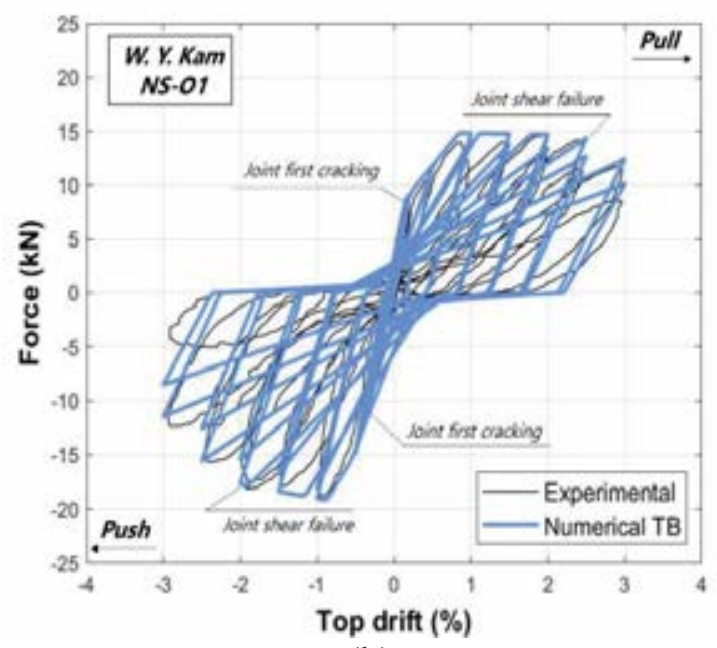

(b)

Figure 5: Horizontal Force - Top drift for specimen NS-O1, comparison between experimental and numerical results. (a) bi-linear backbone, (b) tri-linear backbone.

The bi-linear backbone could not fully reproduce the post-peak behavior of the force-top drift hysteresis, especially in the pull direction, where the higher axial loads were both beneficial 
(confining the cracked joint core) and harmful (additional compressive force that accelerates bar buckling and concrete spalling) to the joint post-cracking behavior.

On the other hand, the monotonic envelope matched well in capturing the peak point as maximum of resistance achieved, in the push direction.

The proposed trilinear backbone model, reported in Figure 5 (b), simulates the response of specimen NS-O1 successfully. However, it slightly overestimates the initial branch slope where the $K_{0}$ initial stiffness intends to capture joints first cracking peak.

The tri-linear hysteresis curve is capable, when compared to the simplified bilinear curve, one in capturing the strength degradation, especially the rapid degradation due to the joint concrete spalled occurred for cumulative damage. In the cyclic analysis, the damage accumulation improved the prediction of the post-peak behavior and was computed by using factors damage 1 and $\beta$, to govern the strength and stiffness degradation reached at the same displacementimposed level and the progressive stiffness degradation as the displacement itself increases.

These aspects related to the decay system evaluation were considered in both numerical simulations from the pinching re-loading curve after one complete pull-push loading cycle.

Indeed, the bi-linear backbone, given its simplicity, can still remain a valuable tool, yet rather advanced, for professional practice, where there is the need to consider the joint deformability. Furthermore, the experienced practitioner can consider for simplicity, a symmetrical resistance peak in the push-pull directions, taking as a reference one the lower of them, being in safety condition. As further developments, for more detailed studies, a trilinear curve might offer a more accurate representation of the initial stiffness and cracking point.

Worth noting that the strength degradation part of the post-peak region can either be modeled as an additional relationship to the bilinear curve model (e.g., Ruaumoko [33]) or be directly integrated in the trilinear curve as herein demonstrated. In both cases, issues associated with the numerical convergence of a pinched and strength degrading hysteresis loop, particularly when running fully dynamic non-linear time-history analysis can be anticipated and should be carefully considered.

\section{PROPOSED BACKBONE VALUES FOR EXTERIOR JOINTS MODEL}

Following the numerical calibration of the backbone curve on the experimental results of specimen NS-O1, similar approach was extended to various experimental tests on external joints specimens available in the literature (e.g. [9-11] and [29-32]).

The intent is to report in a simple way the main parameters that allow the user (be it a researcher or an experienced practitioner) to effectively describe the external joints backbone, selecting the appropriate level of targeted accuracy. It is worth noting that, when evaluating the equivalent joint moment capacity, expressed in terms of: $M_{c r}, M_{y}, M_{u}$, as previously described, it is preferable to evaluate the peak moment $M_{y}$ following Equations (1), (2), (3) as it closely depends on joints geometry, structural details, and axial load variation.

As it can be noted from the calibrations carried out on the proposed experimental tests, the ratio $M_{c r} / M_{y}$ varies in the range $0.4-0.7$ while the ratio $M_{u} / M_{y}$ varies between 0.7-1.

As for the rotations, building on the values suggested by NZSEE2017 Seismic Assessment Guidelines and associated literature $[15,21]$, calibrated values are herein proposed on the basis of the tests shown in Table 2 .

Based on these calibrations, it is possible to define ranges for $\vartheta_{c r}, \vartheta_{y}, \vartheta_{u}$ to be used as simple and practical references for the joints rotations to be adopted in the numerical models, without going through the full $p_{t}-\gamma$ formulation, see Table 3 . 


\section{Calibrated values for the proposed numerical models}

\begin{tabular}{|c|c|c|c|c|c|c|c|c|c|c|c|c|}
\hline \# Reference & ID & $\begin{array}{c}\mathrm{M}_{c r} \\
(\mathrm{kNm})\end{array}$ & $\begin{array}{c}\mathrm{M}_{y} \\
(\mathrm{kNm})\end{array}$ & $\begin{array}{c}\mathrm{M}_{u} \\
(\mathrm{kNm})\end{array}$ & $\begin{array}{c}\mathrm{K}_{0} \\
(\mathrm{kN} / \mathrm{m})\end{array}$ & $\begin{array}{c}\mathrm{K}_{1} \\
(\mathrm{kN} / \mathrm{m})\end{array}$ & $\begin{array}{c}\mathrm{K}_{2} \\
(\mathrm{kN} / \mathrm{m})\end{array}$ & $\begin{array}{c}\vartheta_{\mathrm{cr}} \\
(\mathrm{rad})\end{array}$ & $\begin{array}{c}\vartheta_{\mathrm{y}} \\
(\mathrm{rad})\end{array}$ & $\begin{array}{c}\vartheta_{\mathrm{u}} \\
(\mathrm{rad})\end{array}$ & $M_{c r} / M_{y}$ & $M_{u} / M_{y}$ \\
\hline $\begin{array}{c}1 \text { Pampanin et al } 2003 \text {. } \\
\text { [15] }\end{array}$ & $\mathrm{T} 1$ & $\begin{array}{l}+9 \\
-13\end{array}$ & $\begin{array}{l}+18 \\
-22\end{array}$ & $\begin{array}{l}+18 \\
-22\end{array}$ & $\begin{array}{l}+599 \\
+667\end{array}$ & 0 & 0 & $\begin{array}{l}+0.0015 \\
-0.002\end{array}$ & \pm 0.005 & \pm 0.01 & $\begin{array}{l}0.50 \\
0.59\end{array}$ & 1 \\
\hline $\begin{array}{c}2 \text { Pampanin et al. } 2003 \\
{[15]}\end{array}$ & L1 & $\begin{array}{l}+7 \\
-9\end{array}$ & $\begin{array}{l}+11 \\
-14\end{array}$ & $\begin{array}{l}+11 \\
-14\end{array}$ & $\begin{array}{l}+1050 \\
+1408\end{array}$ & 0 & 0 & $\begin{array}{l}+0.002 \\
-0.003\end{array}$ & \pm 0.005 & \pm 0.01 & $\begin{array}{l}0.64 \\
0.79\end{array}$ & 1 \\
\hline 3 W. Y. Kam 2010 [30] & NSO1 & $\begin{array}{l}+15 \\
-21\end{array}$ & $\begin{array}{l}+28 \\
-36\end{array}$ & $\begin{array}{l}+22 \\
-29\end{array}$ & $\begin{array}{l}+3142 \\
+2150\end{array}$ & $\begin{array}{l}+474 \\
+658\end{array}$ & $\begin{array}{l}-19 \\
-106\end{array}$ & $\begin{array}{c}+0.00085 \\
-0.001\end{array}$ & \pm 0.0075 & $\begin{array}{l}+0.015 \\
-0.012\end{array}$ & $\begin{array}{l}0.55 \\
0.58\end{array}$ & 0.80 \\
\hline \multirow{6}{*}{4 E. Hertanto [29] } & TDP1 & $\begin{array}{l}+16 \\
-19\end{array}$ & $\begin{array}{l}+35 \\
-21\end{array}$ & $\begin{array}{l}+28 \\
-15\end{array}$ & $\begin{array}{l}+2481 \\
+3225\end{array}$ & - & $\begin{array}{l}-258 \\
-156\end{array}$ & $\begin{array}{l}+0.003 \\
-0.0007\end{array}$ & $\begin{array}{l}+0.0065 \\
-0.0045\end{array}$ & $\begin{array}{r}+0.015 \\
-0.018\end{array}$ & $\begin{array}{l}0.46 \\
0.90\end{array}$ & $\begin{array}{l}0.80 \\
0.71\end{array}$ \\
\hline & TDP2 & $\begin{array}{l}+12 \\
-18\end{array}$ & \pm 30 & \pm 24 & $\begin{array}{l}+2513 \\
+1843\end{array}$ & 0 & $\begin{array}{l}-430 \\
-390\end{array}$ & $\begin{array}{l}+0.0006 \\
-0.00075\end{array}$ & \pm 0.0075 & \pm 0.015 & $\begin{array}{l}0.40 \\
0.60\end{array}$ & 0.80 \\
\hline & TDD1 & $\begin{array}{l}+35 \\
-23\end{array}$ & $\begin{array}{l}+35 \\
-23\end{array}$ & $\begin{array}{l}+35 \\
-23\end{array}$ & $\begin{array}{l}+1142 \\
+1804\end{array}$ & - & 0 & $\begin{array}{c}+0.0015 \\
-0.00065\end{array}$ & $\begin{array}{c}+0.0075 \\
-0.004\end{array}$ & $\begin{array}{c}+0.018 \\
-0.01\end{array}$ & 1 & 1 \\
\hline & TDD2 & $\begin{array}{l}+42 \\
-20\end{array}$ & $\begin{array}{l}+50 \\
-28\end{array}$ & $\begin{array}{l}+38 \\
-17\end{array}$ & \pm 1514 & - & $\begin{array}{l}-329 \\
-251\end{array}$ & $\begin{array}{c}+0.0004 \\
-0.00025\end{array}$ & $\begin{array}{r}+0.007 \\
-0.0035\end{array}$ & $\begin{array}{c}+0.020 \\
-0.018\end{array}$ & $\begin{array}{l}0.84 \\
0.71\end{array}$ & $\begin{array}{l}0.76 \\
0.61\end{array}$ \\
\hline & TSP & $\begin{array}{c}+15 \\
-9\end{array}$ & $\begin{array}{l}+25 \\
-14\end{array}$ & $\begin{array}{l}+25 \\
-14\end{array}$ & $\begin{array}{l}+410 \\
-557\end{array}$ & - & 0 & $\begin{array}{c}+0.00090 \\
-0.0015\end{array}$ & $\begin{array}{c}+0.006 \\
-0.003\end{array}$ & $\begin{array}{c}+0.015 \\
-0.01\end{array}$ & $\begin{array}{l}0.60 \\
0.64\end{array}$ & 1 \\
\hline & TSD & $\begin{array}{l}+16 \\
-11\end{array}$ & $\begin{array}{l}+22 \\
-16\end{array}$ & $\begin{array}{l}+22 \\
-16\end{array}$ & $\begin{array}{l}+1267 \\
-1857\end{array}$ & 0 & $\begin{array}{l}-85 \\
-70\end{array}$ & $\begin{array}{c}+0.00090 \\
-0.0015\end{array}$ & $\begin{array}{l}+0.0055 \\
-0.0042\end{array}$ & $\begin{array}{c}+0.018 \\
-0.015\end{array}$ & $\begin{array}{l}0.73 \\
0.69\end{array}$ & 1 \\
\hline 5 U. Akguzel 2011 [31] & 2D1 & $\begin{array}{l}+15 \\
-10\end{array}$ & $\begin{array}{l}+27 \\
-38\end{array}$ & $\begin{array}{l}+19 \\
-30\end{array}$ & $\begin{array}{l}+1890 \\
+2252\end{array}$ & 0 & $\begin{array}{l}-358 \\
-667 \\
\end{array}$ & $\begin{array}{c}+0.0009 \\
-0.00018\end{array}$ & \pm 0.003 & \pm 0.015 & $\begin{array}{l}0.56 \\
0.26\end{array}$ & $\begin{array}{l}0.70 \\
0.79\end{array}$ \\
\hline
\end{tabular}

Table 2: Backbone values used in numerical models' calibration.

\begin{tabular}{cccc}
\hline \multicolumn{4}{c}{ Joint rotations ranges } \\
\hline Joint's type & $\begin{array}{l}\vartheta_{\text {cr }} \\
(\mathrm{rad})\end{array}$ & $\begin{array}{c}\vartheta_{\mathrm{y}} \\
(\mathrm{rad})\end{array}$ & $\begin{array}{c}\vartheta_{\mathrm{u}} \\
(\mathrm{rad})\end{array}$ \\
External & $0.0006 \leq \vartheta \geq 0.0015$ & $0.003 \leq \vartheta \geq 0.0075$ & $0.01 \leq \vartheta \geq 0.02$ \\
\hline
\end{tabular}

Table 3: Proposed ranges for external joints rotations.

Figure 6 shows the envelopes obtained for the experimental tests on external joints analyzed in terms of joint rotation $(\vartheta)$ vs normalized moment $\left(M / M_{y}\right)$. By observing the shape of the proposed curves, it can be seen that on the basis of the case study, the most appropriate backbone was chosen to describe the joints behavior (bi-linear or tri-linear).

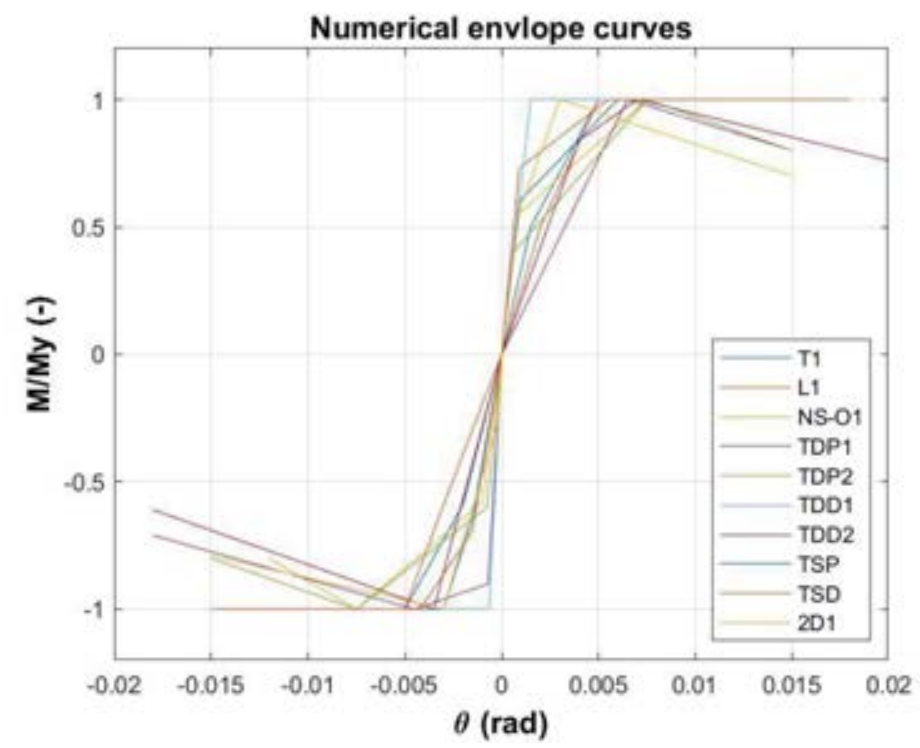

Figure 6: Envelope curves of numerical tests on literature specimens reported in Table 2. 


\section{CONCLUSIONS}

In this paper, an experimental test on an exterior beam-column joint designed for gravity loads has been numerical modelled by a lumped plasticity approach. The joint non-linear deformation capacity represented through a single non-linear rotational spring placed at beam-column intersection. For what concerns the numerical settings, it was necessary to define an efficient moment-rotation relationship allowing to obtain a reliable prediction of the selected exterior joint specimen NS-O1. Moreover, the parameters to be defined were the elastic stiffness, pre- and post-cracking slopes, as well as the pinching behavior, as a function of the type of joints (exterior), joint dimensions, axial load ratio, longitudinal reinforcement type, anchorage details.

Finally, two different backbones were chosen to simulate the experimental test in terms of top force-global drift response. The first one consists of a simple bi-linear relationship, useful for the experienced practitioner, which should adopt the most convenient approach to consider joint deformation capacity, according to NZSEE2017 Seismic Assessment Guidelines [21].

The second one consists of a tri-linear relationship, useful in the research field when the goal is to capture detailed aspects of the experimental test to be reproduced, or in general of the overall joint behavior, depending on the required degree of accuracy and scope of work. In this case, the tri-linear backbone can capture and better model the point of first cracking, the elastic and softening branches.

All the parameters that characterize the backbone curves and their hysteretic behavior are reported, highlighting how the values provided by NZSEE2017 Seismic Assessment Guidelines [21] are intentionally and reasonably providing average behavior, while, for a case-by-case specific analysis, more appropriate parameters can be identified to better describe the joints performances. This work represents a small part of a more extensive numerical simulation campaign on existing joints currently under development.

\section{ACKNOWLEDGEMENTS}

The authors wish to acknowledge the financial support received by the Italian Department of Civil Protection (ReLUIS 2019-2021 Grant - Inventory of existing structural and building types- CARTIS).

\section{REFERENCES}

[1] M. Di Ludovico, A. Digrisolo, F. Graziotti, C. Moroni, A. Belleri, S. Caprili, C. Carocci, A. Dall'Asta, G. De Martino, S. De Santis, B. Ferracuti, D.K Ferretti, G. Fiorentino, A. Mannella, A. Marini, C. Mazzotti, A. Sandoli, A. Santoro, S.M Silvestri, L. Sorrentino, G. Magenes, A. Masi, A. Prota, M. Dolce, G. Manfredi, 2017. The contribution of ReLUIS to the usability assessment of school buildings following the 2016 central Italy earthquake. Bollettino di Geofisica Teorica ed Applicata, 58(4), 353-376.

[2] H. Crowley, R. Pinho, J.J. Bommer, A Probabilistic Displacement-based Vulnerability Assessment Procedure for Earthquake Loss Estimation. Bulletin of Earthquake Engineering 2004; 2(2): 173-219.

[3] J.W. Bake, C.A. Cornell, Uncertainty propagation in probabilistic seismic loss estimation. Structural Safety 2008; 30(3): 236-252. 
[4] F. Romano, M. Faggella, R. Gigliotti, M. Zucconi, B. Ferracuti, Comparative seismic loss analysis of an existing infilled RC building based on element fragility functions proposals. Eng. Struct. 2018; 177: 707-723.

[5] F. Romano, M.S. Alam, M. Zucconi, M. Faggella, A.R. Barbosa, B. Ferracuti, Seismic demand model class uncertainty in seismic loss analysis for a code designed URM infilled RC frame building. Bull. Earthq. Eng. 2021; 19(1): 429-462.

[6] M. Zucconi, M. Sabene, S. Pampanin, B. Ferracuti, Seismic assessment of a RC frame building designed for gravity loads including joint deformation capacity model, Proceedings of Phdsymp 2021.

[7] G. Calvi, G. Magenes, S. Pampanin, Relevance of beam-column joint damage and collapse in rc frame assessment. J. Earthq. Eng., 2002, 6, 75-100.

[8] S. Pampanin, D. Bolognini, A. Pavese, Performance-Based Seismic Retrofit Strategy for Existing Reinforced Concrete Frame Systems Using Fiber-Reinforced Polymer Composites, 2007, J. Compos. Constr., Vol. 11(2), 211-226.

[9] S. Pampanin, G. M. Calvi, M. Moratti, Seismic behaviour of R.C. beam-column joints designed for gravity loads, 12nd European Conf. on Earthquake Engineering, 2002.

[10] A. Masi., G. Santarsiero, D. Nigro, Cyclic tests on external RC beam-column joints: role of seimic design level and axial load value on the ultimate capacity. $J$ Earthquake Eng. 2013;17(1):110-36.

[11] A. Masi., G. Santarsiero, G. P. Lignola, G. M. Verderame, Study of the seismic behavior of external RC beam-column joints through experimental tests and numerical simulations, Eng. Struct., vol. 52, 207-219, 2013.

[12] M. J. N. Priestley, Displacement-based seismic assessment of reinforced concrete buildings, J. Earthq. Eng., 1(1), 1997, 157-192.

[13] C.P. Pantelides, C. Clyde, L.D. Reaveley, Performance-based evaluation of reinforced concrete building exterior joints for seismic excitation. Earthquake Spectra, 2002.

[14] M. Sabene, M. Zucconi, B. Ferracuti, S. Pampanin, Open Issues on Testing and Modeling Existing RC Beam-Column Joints, AIP Conference Proceedings 2293, 240002 (2020).

[15] S. Pampanin, G. Magenes, A. Carr, Modelling of shear hinge mechanism in poorly detailed RC beam-column joints, fib Symposium Concrete Structures in Seismic Regions, 2003, 171.

[16] J. Hegger, A. Sherif, W. Roeser, Nonlinear finite element analysis of reinforced concrete beam-column connections. ACI Struct J, 2004;101(5):604-14.

[17] A.C. Birely, L.N. Lowes, E. Lehman, A model for the practical nonlinear analysis of reinforced-concrete frames including joint flexibility. Eng Struct 2012;34(1):455-65.

[18] M. T. De Risi, P. Ricci, G. M. Verderame, Modelling exterior unreinforced beam-column joints in seismic analysis of non-ductile RC frames, Earthq. Eng. Struct. Dyn., 46, no. 6, pp. 899-923, May 2017.

[19] G. J. O'Reilly, T. J. Sullivan, Modeling Techniques for the Seismic Assessment of the Existing Italian RC Frame Structures, J. Earthq. Eng., 2469, 1-35, 2017.

[20] J. Shayanfar, H. A. Bengar, A. Parvin, Analytical prediction of seismic behavior of RC joints and columns under varying axial load, Eng. Struct. 174 (2018) 792-813. 
[21] NZSEE (2017). New Zealand Society for Earthquake Engineering, Wellington, New Zealand.

[22] S. Pampanin, Alternative Performance-Based Retrofit Strategies and Solutions for Existing RC Buildings, Chapter 13 (267-295) in Seismic Risk Assessment and Retrofitting, Geotechnical, Geological, and Earthquake Engineering 10 (Editors A. Ilki et al.), 2009.

[23] U. Akguzel, S. Pampanin, Assessment and design procedure for the seismic retrofit of reinforced concrete beam-column joints using FRP composite materials. J Compos Constr, 2012.

[24] C. Del Vecchio, M. Di Ludovico, A. Balsamo, A. Prota, Seismic Retrofit of Real BeamColumn Joints using Fiber-Reinforced Cement (FRC) Composites, J. Struct. Eng., 2018,10.1061.

[25] S. Pampanin, Towards the practical implementation of performance-based assessment and retrofit strategies for RC buildings: challenges and solutions", SMAR2017-4th Conf. on Smart Monitoring, Assessment and Rehabilitation of Structures, 2017.

[26] B. Ferracuti, M. Savoia, M. Zucconi, RC frame structures retrofitted by FRP-wrapping: A model for columns under axial loading and cyclic bending. Eng. Struct, 2020; 207: 110243.

[27] M. Zucconi, M. Sabene, M. Kioumarsi, B. Ferracuti, Pre-code RC Bare Frame: seismic retrofit with alternative strategies, AIP Conference Proceedings 2293, 240004 (2020).

[28] C. Del Vecchio, R. Gentile, M. Di Ludovico, M. Uva, S. Pampanin, Implementation and Validation of the Simple Lateral Mechanism Analysis (SLaMA) for the Seismic Performance Assessment of a Damaged Case Study Building, J. Earthq. Eng., 2020, 24(11), 1771-1802.

[29] E. Hertanto, Seismic assessment of pre-1970s reinforced concrete structures, Department of Civil and Natural Resources Engineering, University of Canterbury, 2005

[30] W. Y. Kam, Selective weakening, and post-tensioning fro the seismic retrofit of nonductile RC frames, Department of Civil and Natural Resources Engineering, University of Canterbury, 2010.

[31] U. Akguzel, Seismic performance of FRP retrofitted exterior RC beam-column joints under varying axial and bidirectional loading, Department of Civil and Natural Resources Engineering, University of Canterbury, 2011.

[32] G. Genesio, Seismic assessment od rc exterior beam-column joints and retrofit with haunches using post-installed anchors, Institute for Materials in Construction at the University of Stuttgart, 2011

[33] A. Carr, RUAUMOKO - Inelastic Dynamic Analysis, Department of Civil Engineering, University of Canterbury, 2004. 